\title{
Evaluation of risk factors for ectopic pregnancy among women attending a tertiary care hospital in United Arab Emirates: A case control study
}

\author{
Vaswani $\mathbf{P}^{1}$, Vaswani $\mathbf{R}^{2}$
}

\begin{abstract}
Objective: To evaluate and analyze potential risk factors for ectopic pregnancy in a tertiary care Hospital in United Arab Emirates (UAE).

Methods: A case control study was conducted in Mafraq Hospital from August 2008 to December 2011. The study subjects included 108 women diagnosed with ectopic pregnancy (cases group) and 216 women who delivered in the study hospital during the same time period (control group).
\end{abstract}

Results: In our study population the risk of ectopic pregnancy was found 8 fold more in women who had past history of pelvic inflammatory disease (OR $8.14,95 \% \mathrm{Cl}, 1.90$ $34.77, p=0.005), 6$ fold more in women with infertility (OR 6.57,95\% Cl, 3.06-14.08, $\mathrm{p}=0.000$ ), 3 fold more in women with previous pelvic surgery (OR $3.33,95 \% \mathrm{Cl}, 1.28$ $8.66, p=0.01$ ) and 1.7 fold more in women with previous history of spontaneous miscarriages (OR 1.76, 95\% Cl, 1.03-3.00, $\mathrm{p}=0.03$ ) as compared to those women who had normal delivery.

Conclusion: Results of this study supported the hypothesis that a past history of pelvic inflammatory disease, history of infertility for at least 2 years preceding the ectopic pregnancy, past history of pelvic surgery and previous spontaneous miscarriages are significant risk factors for the occurrence of ectopic pregnancy. Increased awareness and knowledge of risk factors among the women population can enable an early detection and diagnosis of ectopic pregnancy thereby leading to early intervention and conservative approach for management.

Key words: ectopic pregnancy, infertility, pelvic inflammatory disease, pelvic surgery

\section{Introduction}

Ectopic pregnancy is the most common cause of pregnancy related deaths in the first trimester of pregnancy. It accounts for $6-10 \%$ of all pregnancy related deaths ${ }^{1}$. Technological advances in available diagnostic modalities over past few

${ }^{1}$ Specialist in Department of Obstetrics and Gynecology, Mafraq Hospital, Abu Dhabi, UAE.

${ }^{2}$ Department of Anesthesia, Mafraq Hospital, Central Baniyas, Abu Dhabi, UAE.

Correspondence: Pooja Vaswani

E-mail: poojarvaswani@yahoo.co.in

Competing interests: None decades definitely help in earlier diagnosis of ectopic pregnancy. However despite these advances, ectopic pregnancy still remains one of the major contributors towards pregnancy related morbidity and mortality. As per the Confidential Enquiry into Maternal and Child Health (CEMACH) Report, the number of deaths attributed to ectopic pregnancy has increased from 47 in 2002-2004 to 75 in 2008-2010 triennium ${ }^{2}$. Early diagnosis and prompt management thus remains crucial. Studies in Sweden demonstrate that the epidemiology of ectopic pregnancy closely mirrors the epidemiological trends in the occurrence of pelvic inflammatory disease and of some sexually transmitted infections ${ }^{3,4}$. There are several other risk factors potentially associated with the occur- rence of ectopic pregnancy like previous ectopic pregnancy, previous pelvic surgery and history of infertility; however the role played by these factors remains unclear. The aim of this study was to identify risk factors for ectopic pregnancy and to analyze the associations of these risk factors with ectopic pregnancy in a tertiary care hospital in United Arab Emirates'.

\section{Methods}

This was a retrospective, case control study conducted in Mafraq Hospital between August 2008 and December 2011. Approval for the study was sought from the Hospital's Research and Ethics Committee. The study included 108 women diagnosed to have ectopic pregnancy. These women constituted "Cases" group. For every single selected case of ectopic pregnancy, 2 women who delivered at term in the same hospital on the same day were taken as controls. Thus the "Control" group comprised of 216 women.

The information was collected for each subject in a pre-designed and pretested proforma on her obstetric history and gynecological history, past history of any pelvic surgical procedures, previous history of curettage, previous history of pelvic inflammatory disease (PID), intrauterine contraceptive device (IUCD) use (current or in past) and history of infertility of 2 or more years preceding the diagnosis of ectopic pregnancy.

Statistical analyses were carried out in STATA software version 10.1, 2009, and Epi Info version 7.1.0.6, 2012. In univariate analysis frequency distri-butions were generated for each variable separately. Categorical variables were summarized in percentages and continuous variables in terms of mean and standard deviation. A standard case control analysis strategy 
was followed due to retrospective nature of the study design. In bivariate analyses, differences in percentages between the comparison groups were tested by Chi-square test and the differences in means were tested by $\mathrm{t}$ test. Crude estimates of odds ratio (OR) were calculated to quantify association between various risk factors and an ectopic pregnancy. In multivariate ana-lyses, unconditional, multiple logistic regression models were used to obtain estimates of ORs accounting for the role of confounders. A p value less than 0.05 was considered statistically significant.

Table 1. Distribution of age and parity among controls and cases

\begin{tabular}{lrrrrr}
\hline Characteristics & \multicolumn{2}{c}{$\begin{array}{c}\text { Controls } \\
(n=216)\end{array}$} & \multicolumn{3}{c}{$\begin{array}{c}c \\
(n=108)\end{array}$} \\
& No. & $(\%)$ & \multicolumn{2}{c}{ No. } & $(\%)$ \\
\hline Age (years) & & & & & \\
$18-25$ & 31 & $(14.35)$ & 18 & $(16.66)$ \\
$26-35$ & 119 & $(55.09)$ & 58 & $(53.70)$ \\
$36-40$ & 47 & $(21.75)$ & 23 & $(21.29)$ \\
$>40$ & 19 & $(8.79)$ & 9 & $(8.33)$ \\
Parity & & & & & \\
Nulliparous & 28 & $(12.96)$ & 22 & $(20.37)$ \\
$1-4$ & 130 & $(60.18)$ & 61 & $(56.48)$ \\
$5-9$ & 56 & $(25.92)$ & 24 & $(22.22)$ \\
10 or more (years) & 2 & $(0.92)$ & 1 & $(0.92)$ \\
\hline
\end{tabular}

\section{Results}

A total of 324 pregnant women were included in this study. 108 (33.33\%) subjects diagnosed with ectopic pregnancy formed the "Cases" group and 216 (66.66\%) women who delivered during the same period in the same hospital comprised "Control" group. Age and parity in two groups were found almost comparable (Table 1). Mean ( \pm standard deviation) age of cases was $31.75 \pm 6.12$ years and in control group it was $31.86 \pm 6.14$ years. Mean ( \pm standard deviation) parity in cases was $2.72 \pm 2.25$ and $2.86 \pm 2.24$ in controls. Results of bivariate analyses are summarized in Table 2. The factors which appeared to be significantly associated with the risk of ectopic pregnancy on bivariate analysis were previous history of spontaneous miscarriages, infertility of 2 or more years preceding the diagnosis of ectopic pregnancy, previous history of PID, previous pelvic surgeries and past IUCD use. These factors were also found to be significantly associated with the occurrence of ectopic pregnancy in multivariate analysis after adjustment for confounders (Table 3).

Table 2. Association of potential risk factors with ectopic pregnancy on bivariate analyses

\begin{tabular}{|c|c|c|c|c|c|c|c|}
\hline \multirow[t]{2}{*}{ Risk factor } & \multicolumn{2}{|c|}{$\begin{array}{l}\text { Controls } \\
(n=216)\end{array}$} & \multicolumn{2}{|c|}{$\begin{array}{l}\text { Cases } \\
(n=108)\end{array}$} & \multirow[t]{2}{*}{ Odds ratio } & \multirow[t]{2}{*}{$95 \% \mathrm{Cl}$} & \multirow[t]{2}{*}{$p$ value } \\
\hline & No. & $\%$ & No. & $\%$ & & & \\
\hline $\begin{array}{l}\text { Past history of spontaneous } \\
\text { miscarriages }\end{array}$ & 51 & 47.22 & 77 & 36.11 & 1.61 & $0.98-2.65$ & 0.04 \\
\hline History of infertility & 29 & 26.85 & 14 & 6.48 & 5.29 & $2.53-11.38$ & 0.000 \\
\hline Past history of PID & 9 & 8.33 & 3 & 1.38 & 6.45 & $1.55-37.62$ & 0.001 \\
\hline $\begin{array}{l}\text { Past history of } \\
\text { ectopic pregnancy }\end{array}$ & 10 & 9.25 & 9 & 4.16 & 2.34 & $0.82-6.73$ & 0.06 \\
\hline Past history of pelvic surgery & 15 & 13.88 & 9 & 4.16 & 3.70 & $1.45-9.94$ & 0.001 \\
\hline Past history of curettage & 15 & 13.88 & 19 & 8.79 & 1.6 & $0.75-3.64$ & 0.15 \\
\hline Past use of IUCD & 7 & 6.48 & 3 & 1.38 & 4.92 & $1.08-29.93$ & 0.012 \\
\hline
\end{tabular}


Table 3. Association of potential risk factors with ectopic pregnancy on multivariate analyses

\begin{tabular}{|c|c|c|c|c|c|c|c|}
\hline \multirow[t]{2}{*}{ Risk factor } & \multicolumn{2}{|c|}{$\begin{array}{l}\text { Controls } \\
(n=216)\end{array}$} & \multicolumn{2}{|c|}{$\begin{array}{l}\text { Cases } \\
(n=108)\end{array}$} & \multirow[t]{2}{*}{$\begin{array}{l}\text { Adjusted } \\
\text { Odds ratio }\end{array}$} & \multirow[t]{2}{*}{$95 \% \mathrm{Cl}$} & \multirow[t]{2}{*}{$p$ value } \\
\hline & No. & $\%$ & No. & $\%$ & & & \\
\hline $\begin{array}{l}\text { Past history of spontaneous } \\
\text { miscarriages }\end{array}$ & 51 & 47.22 & 77 & 36.11 & 1.76 & $1.03-3.00$ & 0.03 \\
\hline $\begin{array}{l}\text { History of infertility in } \\
\text { preceding } 2 \text { years }\end{array}$ & 29 & 26.85 & 14 & 6.48 & 6.57 & $3.06-14.08$ & 0.000 \\
\hline Past history of PID & 9 & 8.33 & 3 & 1.38 & 8.14 & $1.90-34.77$ & 0.005 \\
\hline Past history of pelvic surgery & 15 & 13.88 & 9 & 2.47 & 3.33 & $1.28-8.66$ & 0.01 \\
\hline Past use of IUCD & 7 & 6.48 & 3 & 1.38 & 4.17 & $0.98-17.75$ & 0.05 \\
\hline
\end{tabular}

Cases were more than 8 times likely to have a history of PID in past (OR 8.14, 95\% CI, 1.90-34.77, $\mathrm{p}=0.005$ ) and more than 6 times likely to have a history of infertility for at least 2 years preceding the diagnosis of ectopic pregnancy (OR 6.57,95\% CI, 3.06$14.08, p=0.000)$ as compared to controls. Further, the women with ectopic pregnancy were more than 3 times likely to have a past history of any pelvic surgery like appendectomy, ovarian cystectomy or surgery for pelvic endometriosis in comparison to controls (OR 3.33, 95\% CI, 1.28-8.66, $\mathrm{p}=0.01)$ and 1.7 times more likely to have a past history of spontaneous miscarriages (OR 1.76, 95\% CI, 1.033.00, $\mathrm{p}=0.03$ ). However, the past use of IUCD had shown only borderline significance ( $\mathrm{p}-0,05)$ after adjustment for other risk factors.

\section{Discussion}

Exact etiology of ectopic pregnancy is still not known. Pathogenesis of ectopic pregnancy remains multifactorial $^{5,6}$. Literature suggests contribution of several risk factors in the etiology of ectopic pregnancy ${ }^{7-11}$. Knowledge of risk factors in a particular women population and their identification in an individual patient definitely seems important and is expected to contribute towards an early diagnosis of 'at risk' cases. Earlier studies by many authors have reported an increased risk of ectopic pregnancy in women with previous history of pelvic infections ${ }^{7-11}$. In fact past pelvic inflammatory disease has been shown to be the strongest predictor in some studies ${ }^{6,11-13}$. After the resolution of the inflammatory process, the resulting fibrosis ultimately leads to distortion of the fallopian tubes, narrowing of tubal lumen or intratubal adhesions which can impede the passage of the ovum and may favor implantation in blind pockets of adhesions. The post inflammatory damage can on one hand reduce the woman's chances of conception leading to diminished fertility and on the other hand may predispose the woman to tubal pregnancy. Our results are comparable to those of Westrom et al who reported that ectopic pregnancy is 7 times more likely in women with past history of pelvic infection as compared to controls ${ }^{11}$.

The contribution of chronic impairment of the reproductive function predisposing to ectopic pregnancy can be demonstrated by the increased chances of recurrence of ectopic pregnancy among women who have had an ectopic pregnancy before ${ }^{1}$. In our study also 10 (9.25\%) women with ectopic pregnancy (cases) had a past history of ectopic pregnancy, and 4 out of these 10 women had ectopic pregnancy twice before. On the other hand only $9(4.16 \%)$ women in the control group had past history of ectopic pregnancy once. Though previous ectopic pregnancy did not turn out to be significant risk factor in the present study, but the magnitude of odds ratio of 2.34 and $95 \%$ confidence interval of 0.82 - 6.73 (Table 2) did suggest that past history of ectopic pregnancy could be an important associated risk factor. Small number of the study subjects with previous ectopic pregnancy in our study restricts us to make any conclusive comment on this association.

Infertility and ectopic pregnancy have been shown to be inter-related and share some common predisposing factors. This association is explained when contribution of PID towards tubal damage is understood as described before. Earlier studies by many authors have endorsed this association $7,8,10,14$. Study by Bunyavejchevin et al from Thailand shows women with past infertility to be 3 times more at risk of ectopic pregnancy. Another study by Marchbanks et al from Atlanta shows such women to be about 2.6 times more at risk of ectopic pregnancy. In our study we found this association to be even stronger as infertile women were carrying almost 6 times increased risk of ectopic pregnancy than controls.

Past pelvic surgery can favor adhesion formation and thus may distort the fallopian tubes and consequently predisposes the woman 
for ectopic pregnancy. Results of our study are in agreement with other studies and show an increased risk of ectopic pregnancy in women with previous pelvic surgery ${ }^{8-10}$. The risk of ectopic pregnancy was found to be more than 3 times increased in these women in our study. Earlier studies have found a significant contribution of previous tubal surgery in predisposing a woman for ectopic pregnancy ${ }^{7,10}$. In our study however the association of previous tubal surgery with ectopic pregnancy could not be evaluated due to small number of occurrence of this exposure - only two subjects in case group and no subjects in control group had past history of tubal surgery.

Previous use of intrauterine contraceptive device has been shown to increase the risk of ectopic pregnancy 3 to 4 folds in previous studies $8,8,15,16$. Previous intrauterine device use has an etiologic role in ectopic pregnancy per se, not only through an association with infection as previously suggested [17]. In our study the association of past use of IUCD with ectopic pregnancy was also found to be significant on bivariate analysis (OR 4.92, 95\% CI, 1.08-29.93, $p=0.012)$. But after adjustment for confounders, the association was reduced to borderline significance (OR 4.17, 95\% CI, 0.9817.75, $\mathrm{p}=0.05)$. Though confidence interval is wide and includes unity as well, but it is indicative of the association going away from the null. Increased risk of ectopic pregnancy when the conception occurs despite an IUCD in place has been shown in some studies ${ }^{7,10,18}$. Marchbanks et al indeed found this risk to be increased by as high as 13 fold $^{7}$. In our study there was only one woman who had ectopic pregnancy with an IUCD in situ and none of the women in control group had conceived with an IUCD in situ. Consequently we could not evaluate this risk factor.

Few studies have reported past spontaneous miscarriages as a predisposing risk factor for ectopic pregnancy ${ }^{9,16,19}$. This association may possibly be mediated through infection or via common risk factors for ectopic pregnancy and spontaneous miscarriages such as chromosomal abnormalities or hormonal factors. In our study we found a 1.7 fold increased risk of ectopic pregnancy in women with past history of spontaneous miscarriages.

Literature documents that ectopic pregnancy is generally most common in women $\geq 25$ years of age ${ }^{14}$ whereas majority of PID admissions are for the younger age women ${ }^{13,20}$. This difference in age groups at risk of PID and of ectopic pregnancy is understandable because ectopic pregnancy is considered to be late sequelae of PID. Kamwendo et al in their study have also found the peak incidence of ectopic pregnancy in women 25 years or older ${ }^{3}$. Westrom et al from Sweden and Rubin et al from USA reported the incidence of ectopic pregnancy increasing with age ${ }^{11,21}$. Increased incidence of ectopic pregnancy with multiparity has been reported by some studies $^{19,22}$. However in our study, distribution of age and parity among cases and controls was found comparable. History of multiple lifetime sexual partners, early age of sexual intercourse, induced abortions and smoking are few other risk factors found to be associated with ectopic pregnancy ${ }^{9}$. These factors could not be evaluated in our study as sufficient data could not be obtained for these factors owing to various socio-cultural and religious reasons prevalent in the study population. Results of this study support the hypothesis that a past history of pelvic inflammatory disease, history of infertility for at least 2 years preceding the ectopic pregnancy, past history of pelvic surgery and previous spontaneous miscarriages are significant risk factors for the occurrence of ectopic pregnancy and all these factors in combination increase the risk by 8 folds, 6 folds, 3 fold and 1.7 folds respectively. A strong possibility of association of past intrauterine contraceptive device use with the occurrence of ectopic pregnancy is likely, however studies with larger sample sizes are needed to assert this association.

\section{Conclusions}

Increasing our knowledge of risk factors for ectopic pregnancy in the local population in UAE can help in improving our understanding of the important factors contributing towards ectopic pregnancy and it also helps during counseling and development of preventative strategies. While dealing with a patient presenting with suspected ectopic pregnancy, presence of any of the risk factors can help in an early detection and diagnosis of ectopic pregnancy thereby leading to early intervention and conservative approach for management.

\section{REFERENCES}

1. Chavkin W. The rise in ectopic pregnancyexploration of possible reasons. Int $\mathrm{J}$ Gynaecol Obstet.1982 ; 20(4): 341-50.

2. Confidential Enquiry into Maternal and Child Health, 2008-2010, RCOG, UK.

3. Kamwendo F, Forslin L, Bodin L, Danielsson D. Epidemiology of ectopic pregnancy during a 28 -year period and the role of pelvic inflammatory disease. Sex Transm Infect 2000; 76(1): 28-32.

4. Bjartling C, Osser S, Persson K. The frequency of salpingitis and ectopic pregnancy as epidemiologic markers of Chlamydia trachomatis. Acta Obstet Gynecol Scand 2000; 79(2): 123-8.

5. Pisarska MD, Carson SA, Buster JE. Ectopic pregnancy. Lancet 1998; 351: 1115-20.

6. Ankum WM, Mol BWJ, Van der Veen F, et al. Risk factors for ectopic pregnancy: a meta-analysis. Fertil Steril 1996; 65: 1093-9.

7. Marchbanks PA, Annegers JF, Coulam $\mathrm{CB}$, Strathy JH, Kurland LT. Risk factors for ectopic pregnancy. A population-based study. JAMA 1988 25; 259(12): 1823-7.

8. Tuomivaara L, Kauppila A. Ectopic pregnancy: a case-control study of aetiological risk factors. Arch Gynecol Obstet. 1988; 243(1): 5-11.

9. Anorlu RI, Oluwole A, Abudu OO, Adebajo S. Risk factors for ectopic pregnancy in Lagos, Nigeria. Acta Obstet Gynecol Scand 2005; 84(2): 184-8.

10. Nordenskjöld F, Ahlgren M. Risk factors in ectopic pregnancy. Results of a populationbased case-control study. Acta Obstet Gynecol Scand. 1991; 70(7-8): 575-9. 
11. Weström L, Bengtsson L Ph, Mårdh P-A. Incidence, trends and risks of ectopic pregnancy in a population of women. BMJ 1981; 282: 15-18.

12. Clark K, Baranyai J. Pelvic infection and the pathogenesis of tubal ectopic pregnancy. Aust NZ J Obstet Gynaecol 1987; 27 : 57-60.

13. Hadgu A, Koch G, Weström L. Analysis of ectopic pregnancy data using marginal and conditional models. Statist Med 1997; 16 : 2403-17.

14. Bunyavejchevin $S$, Havanond $P$, Wisawasukmongchol W. Risk factors of ectopic pregnancy. J Med Assoc Thai. 2003; 86 Suppl 2: S417-21.

15. Parazzini F, Ferraroni M, Tozzi L, Benzi G, Rossi G, La Vecchia C. Past contraceptive method use and risk of ectopic pregnancy. Contraception 1995; 52(2): 93-8.

16. Bouyer J, Rachou E, Germain E, Fernandez H, Coste J, Pouly $\mathrm{JL}$, Job-Spira N. Risk factors for extrauterine pregnancy in women using an intrauterine device. Fertil Steril. 2000; 74(5): 899-908.
17. Jean Bouyer, Joël Coste, Taraneh Shojaei et al. Risk Factors for Ectopic Pregnancy: A Comprehensive Analysis Based on a Large Case-Control, Population-based Study in France. Am J Epidemiol 2003; 157: 185-94.

18. Rossing MA, Daling JR, Voigt LF, Stergachis AS, Weiss NS. Current use of an intrauterine device and risk of tubal pregnancy. Epidemiology. 1993; 4(3): 252-8.

19. Shaista Aziz, Bothaina AI Wafi, Hussain AI Swadi. Frequency of Ectopic Pregnancy in a Medical Centre, Kingdom of Saudi Arabia. J Pak Med Assoc. 2011; 61(3).

20. Weström L. Incidence, prevalence, and trends of acute pelvic inflammatory disease and its consequences in industrialized countries. Am J Obstet Gynecol 1980; 138: 880-92

21. Rubin GL, Peterson HB, Dorfman SF, et al. Ectopic pregnancy in USA 1970 through 1978. JAMA 1983; 249 : 1725.

22. Gaddagi RA, Chandrashekhar AP. A Clinical Study of Ectopic Pregnancy Journal of Clinical and Diagnostic Research. 2012; 6(5): 867-9.

\section{Erratum}

Volume 35, No 1, March 2013

\section{Obesity in pregnancy - The bigger issues}

\section{Page 31: Cesarean section}

'If the pannus can be retracted cephalad without causing respiratory compromise, a subumbilical incision is preferred'

\section{Should be changed to}

'Overall, evidence suggests that if the pannus can be retracted cephalad without causing maternal hypotension or respiratory compromise a low transverse incision is preferred' 